\title{
AFFECTIVE ECOLOGICAL RESTORATION, BODIES OF EMOTIONAL PRACTICE
}

LILIAN M. PEARCE

\section{Abstract}

Ecological restoration is an emotional practice. Through restoration, practitioners engage in personal and palpable relationships with their local ecosystems. This paper draws on participatory social research with volunteer groups on the south-east coast of New South Wales, Australia. Here, ecological restoration volunteers react to the cumulative impacts of agriculture, mining, forestry and fishing on local ecosystems. Five affective experiences within the practice-loving, labouring, learning, limiting and letting go-convey the significance of emotions in renegotiating relationships with place. Colonially framed social and ecological imaginaries are unravelled through the cultivation of reciprocal, attentive and caring encounters with the environment. As well as reframing the past, comments such as 'this whole project in a way is looking after a landform which in all likelihood will totally disappear' suggest the importance of commitment in the present, amidst an uncertain future. This paper contributes to discussions about the changing role of history in contemporary ecological restoration. Histories of human-environment relationships extending back to colonial visions of Australia are repeatedly encountered and complicated through engagements with material ecologies and the affective experiences of restoration work.

Keywords: ecological restoration, environmental history

\section{Introduction}

'Ecological restoration is rooted in ecological history', assert the ecologists Stephen Jackson and Richard Hobbs. Yet, they continue, 'the environment has drifted, and so too have the targets'. Goals of historical fidelity-returning to a pre-disturbance or 'original' ecosystem - have traditionally legitimised ecological restoration within the environmental sciences and defended it from philosophical critiques. However, this article suggests that a nostalgia-fuelled narrative is fraught with ignorance, omission and impossibility. Amidst global change, scientists working practically in this area contest the plausibility of returning to fixed 'ecological baselines', and propose 
alternative uses of history in ecological restoration. ${ }^{1}$ In 2016, a path-breaking paper in the journal Ecological Restoration by Eric Higgs and others presented a 'version 2' of the role of history: as a guide for restoration, rather than as an exact template. ${ }^{2}$ Higgs and his colleagues make three justifications: that Indigenous peoples' influence on pre-settler ecologies destabilises colonial ideas of 'pristine' nature; that ecological systems are dynamic, with some reaching irreversible 'novel' states; and that the dramatic social and ecological change of the Anthropocene has purloined hopes of complete ecological return. History in their 'version 2' acts as a tool to interrogate and construct narratives about such issues as ecological cycles, species mobility, ecosystem contingencies, mythologies and moral dilemmas that arise through restoration practice. In this form, history as a tool expands the interpretation of science, identifies key ecological legacies and influences the choices available to restoration practitioners. This suggests an additional element of history's place in restoration work. To make change, ecological restoration cannot simply draw on history as a version of the existing dominant narrative. Instead, ecological restoration must, in part, connect with and write new histories as well.

Already, restoration of 'moral value', attention to 'layered landscapes' and 'landscape legacy' are proposed for thinking restoration differently in the context of the Anthropocene. ${ }^{3}$ The ecologist David Bowman advises that to sufficiently understand and respond to global climate change, land managers and ecologists need to 'think beyond their local environment and put their problems into a historical context'. ${ }^{4}$ The shifting scientific discourses concerning ecological restoration are traceable within place-based historico-cultural contexts. In Australia, where this study is based, history manifests itself powerfully as a series of path dependencies extending back to colonial visions of Australia that saturate human-environment relationships.

1 S. T. Jackson and R. J. Hobbs, 'Ecological restoration in the light of ecological history', Science 325 (2009), 567-8, doi.org/10.1126/science.1172977; P. S. Alagona, J. Sandlos, and Y. F. Wiersma, 'Past imperfect: Using historical ecology and baseline data for conservation and restoration projects in North America', Environmental Philosophy 9, no. 1 (2012): 49-70, doi.org/10.5840/envirophil2012914.

2 E. Higgs, D. A. Falk, A. Guerrini, M. Hall, J. A. Harris, R. J. Hobbs, S. T. Jackson, J. M. Rhemtulla and W. Throop, 'The changing role of history in restoration ecology', Frontiers in Ecology and the Environment 12 (2014): 499-506, doi.org/10.1890/110267.

3 Y. Rohwer and E. Marris, 'Renaming restoration: Conceptualizing and justifying the activity as a restoration of lost moral value rather than a return to a previous state', Restoration Ecology 24, no. 5 (2016): 674-9, doi.org/10.1111/ rec.12398; M. Hourdequin and D. G. Havlick, eds, Restoring Layered Landscapes: History, Ecology and Culture (New York: Oxford University Press, 2016); B. Cook and R. Lane, 'Re-thinking rural-amenity ecologies for environmental management in the Anthropocene', Geoforum 65 (2015): 232-42, doi.org/10.1016/j.geoforum.2015.08.007. See also J. A. Harris, R. J. Hobbs, E. Higgs and J. Aronson, 'Ecological restoration and global climate change', Restoration Ecology 14, no. 2 (2006): 170-6, doi.org/10.1111/j.1526-100X.2006.00136.x, and L. Head, B. Larson, R. Hobbs, J. Atchison, N. Gill, C. Kull and H. Rangan, 'Living with invasive plants in the Anthropocene: the importance of understanding practice and experience', Conservation and Society 13, no. 3 (2015): 311-18, doi.org/10.4103/09724923.170411.

4 D. M. J. S. Bowman, 'Future eating and country keeping: What role has environmental history in the management of biodiversity?', Journal of Biogeography 28, no. 5(2001): 549-64, doi.org/10.1046/j.1365-2699. 2001.00586.x. 
The practice of ecological restoration contributes to ideas about what "belongs" ecologically and culturally across the broad continent of this relatively young postSettler nation'. ${ }^{5}$ In so doing, it has the potential to both reinforce and challenge colonial imaginaries.

Hands-on ecological restoration brings social, cultural and ethical considerations to the foreground, through an 'experiential bridge between people and land'. ${ }^{6}$ Those working on ecological restoration projects understand that they can never entirely recreate a historical state. Rather, local ecological contingencies from a particular point in history foreground a dialogue with the past in decision-making that can achieve important political and ethical work. This article looks to people inside ecological communities, drawing on research conducted in November 2015 with two volunteer restoration groups on the south-east coast of New South Wales (NSW), Australia. ${ }^{7}$ Through place-based environmental practices, discordances emerge between the histories written and told, and the histories encountered and drawn upon. Five affective encounters-loving, labouring, learning, limiting and letting go-illustrate how the practice of restoration provides opportunities to confront and counter dominant histories. Through phenomenological, meaningful encounters with non-human others and observation-based learning, the land insists on new stories. ${ }^{8}$

5 D. Trigger, J. Mulcock, A. Gaynor and Y. Toussaint, 'Ecological restoration, cultural preferences and the negotiation of "nativeness" in Australia', Geoforum 39 (2008): 1273-83, doi.org/10.1016/j.geoforum.2007.05.010. See also M. Adam, 'Foundational Myths: Country and conservation in Australia', Transforming Cultures 3, no. 1 (2008): 291-317, doi.org/10.5130/tfc.v3i1.684.

6 G. Van Wieren, Restored to Earth: Christianity, Environmental Ethics and Ecological Restoration (Washington, DC: Georgetown University Press, 2013), 2. See also D. T. Spencer, 'Ethics and Restoration: A Fascinating and Vexing Time', Society for Ecological Restoration News 30, no. 4 (2016); D. T. Spencer, 'Recreating [in] Eden: Ethical Issues in Restoration in Wilderness', in Placing Nature on the Borders of Religion, Philosophy and Ethics, ed. M. H Dixon and F. Clingermann (New York: Routledge, 2016), Chap. 4; and J. Keulartz, 'The Emergence of Enlightened Anthropocentrism in Ecological Restoration', Nature and Culture 7, no. 1 (2012): 48-71, doi.org/10.3167/ nc.2012.070104.

7 Over three weeks in November 2015, I interviewed restoration volunteers, researched archival materials, walked the land being restored and participated in restoration activities. I focused on two projects: Long Swamp, with Bermagui Flora and Fauna Reserve Trust; and Cuttagee Point, with Bermagui Dune Care. Fieldnotes, personal reflections, archival material and transcripts of interviews inform this work. Due to requests for anonymity, pseudonyms have been used and specific locations have been omitted where possible. Certain aspects of engagement with Aboriginal people and culture in restoration projects have been deliberately omitted at the request of some participants concerned about how the groups are portrayed. The research was conducted with the approval of the Melbourne University Human Ethics Committee, number 1545274.1.

8 In doing so, it takes seriously the corporeal turns in philosophy. See M. Merleau-Ponty, Phenomenology of Perception (Routledge: London, 1962). For an example of the application of this theory to outdoor education, see P. G. Payne and B. Wattchow, 'Phenomenological deconstruction, slow pedagogy, and the corporeal turn in wild environmental/outdoor education', Canadian Journal of Environmental Education 14, no. 1 (2009): 15-32. 


\section{Ecological restoration as emotional practice}

Ecological restoration responds to ecological disturbance, most often of human origin, and aims to return an ecosystem to a pre-disturbance state. 'Emotion' itself refers to a public disturbance, from Old French emouvoir, which means 'to stir up'. Emotions have been considered previously within ecological restoration discourse, particularly with regard to shame and grief.' I take the emotions experienced through restoration to be central to the practice itself-part of Higgs' proposal to think of 'restoration as conversation'. ${ }^{10}$ Thus, loss, nostalgia, disappointment, frustration, hope and love all form part of the restoration praxis, by cultivating new knowledge, reflection and conversation. Emotions are foundational to decisions concerning management practices and the idealisation of historical states. Monique Scheer argues that 'conceiving of emotions as practices means understanding them as emerging from bodily dispositions conditioned by a social context, which always has cultural and historical specificity. ${ }^{11}$ Restoration practices operate inside cultural and historical constructions and are bound up in emotional practices involving 'the self (as body and mind), language, material artefacts, the environment, and other people' ${ }^{12}$ Emotions are not just something that one experiences, but also something that one does with practical outcomes, providing a useful forum within which to challenge and respond to broader colonial legacies. ${ }^{13}$

In Australia, notions of 'pristine' nature are often associated with pre-invasion characteristics, shaped by normative cultural constructs and misconstrued social and ecological imaginaries. Colonial reference points reinforce the dominance of settler experience and the hegemony of Western science, repressing alternative perspectives and ways of being with country. The social theorist Paul Gilroy suggests that ' $[\mathrm{w}] \mathrm{e}$ need to know what sorts of insight and reflection might actually help increasingly differentiated societies and anxious individuals to cope successfully with the challenges involved in dwelling comfortably in proximity to the unfamiliar without becoming fearful and hostile'. ${ }^{14}$ Gilroy's call becomes ever more relevant amid the ecological effects of climate change. As Tom Bristow and I put it:

\footnotetext{
9 R. J. Hobbs, 'Grieving for the Past and Hoping for the Future: Balancing Polarizing Perspectives in Conservation and Restoration', Restoration Ecology 21 (2013): 145-8, doi.org/10.1111/rec.12014; W. R. Jordan III, The Sunflower Forest: Ecological Restoration and the New Communion with Nature (Berkeley CA: University of California Press, 2003).

10 E. Higgs, Nature by Design (Cambridge, MA: MIT Press, 2003).

11 M. Scheer, 'Are emotions a kind of practice (and is that what makes them have a history)? A Bourdieuian approach to understanding emotion', History and Theory 51, no. 2 (2012): 193-220, doi.org/10.1111/j.14682303.2012.00621.x.

12 Scheer, 'Are emotions a kind of practice?', 193.

13 R. C. Solomon, True to Our Feelings: What Our Emotions Are Really Telling Us (New York: Oxford University Press, 2007), 3.

14 P. Gilroy, Postcolonial Melancholia (New York: Columbia University Press, 2005), 3.
} 
Changes to species and ecosystems, to seasons and cycles will soon-if they have not already - contort our relationships with place, requiring us to rethink notions of belonging in order to guide ethically responsible, affectively informed actions that account for humans, non-humans and future generations. ${ }^{15}$

Val Plumwood's approach, which 'asks the human to query herself, and seeks to open the human to the experience of others in the contexts of their own communicative and expressive lives', presents an opportunity to navigate the role of history in ecological restoration and arising ethical questions through affective human relationships. ${ }^{16}$ This must be done in place, in the continual unfolding webs of relationships of biotic and abiotic lives and imaginaries bounded by space.

\section{Introducing Bermagui}

The air is salty, sweet and full of life. Freshwater lagoons are bordered by forest and scrub to the west and the vast ocean to the east. Local ecological communities are diverse: spotted gum woodland; sweet pittosporum low closed forest; heath-leaved paperbark scrub; cumbungi and spike rush bushland; kangaroo grass/bladey grass grassland; coastal wattle/coastal beard heath heathland; coastal salt-bush/coastal rosemary/coastal banksia heathland; drooping she-oak woodland. ${ }^{17}$ The edges of ecological communities are always the richest in species. Edge ecology and the delineated transitional ecosystems are 'ecotones', shading from one group of species into the next. ${ }^{18}$

Taglines for tourism along the NSW South Coast include phrases like 'Sapphire Coast: Beautifully Uncivilised' and 'Australia's Coastal Wilderness: Embrace Something Wild', but it is far from wilderness. ${ }^{19}$ Layers of diverse Indigenous culture, a gold-rush tent city, forestry and fishing industries, cattle grazing and farming pursuits (amongst them ostrich, potatoes and peas) and development disrupt this marketing fantasy. These days, retirement and tourism ventures dominate. On 21 April 1770, Captain James Cook passed this piece of coast and named Mount Dromedary (now known again by its original name Gulaga).$^{20}$ It was not until 1797 that European survivors from the wreck of the Sydney Cove stepped

15 T. Bristow and L. M. Pearce, 'Editorial-Place: Emotional Practices, Geographical Perspectives', PAN: Philosophy, Activism, Nature 12 (2016): 1.

16 D. B. Rose, 'Val Plumwood's philosophical animism: attentive interactions in the sentient world', Environmental Humanities 3 (2014): 93-109, doi.org/10.1215/22011919-3611248.

17 G. Quint, Bermagui Flora and Fauna Reserve Bushland Survey (Sydney: National Trust (NSW), 1986), BFFRT archives.

18 The history of the concept 'ecotones' had an important role in shifting conservation science to whole-oflandscape approaches. See P. G. Risser, 'The status of the science examining ecotones', BioScience 45, no. 5 (1995): 318-25, doi.org/10.2307/1312492.

19 See www.sapphirecoast.com.au and www.australiascoastalwilderness.com.au/embrace, accessed 1 November 2017.

20 B. Davidson, 'History of Bermagui and the District', Tales of the Far South Coast 1 (1982): 14. 
ashore onto land of the Dyirringany people of the Yuin Aboriginal language group. Impacts of European invasion in the area dramatically altered local ecology and culture.

The ancient geomorphology, limnology and ecology of the place have been foundational to the settlement and growth of Bermagui. An article in the Sydney Mail described Bermagui thus:

The massive, stately spotted gum-trees, the iron barks, and the stringybarks of the locality excited the admiration of many of the diggers, many of whom declared they had never seen a country better timbered ... Bermagui has wood, water, and gold, and the population to properly develop its resources. ${ }^{21}$

Only a small dune system divides the freshwater wetland, known commonly today as 'Long Swamp', from the ocean at Haywards Beach. Just one week after the initial discovery of gold in a gully running seaward, in 1880, 'three hundred men' flocked to the seaside, until the beach ground adjacent to Long Swamp was 'pegged out from Bermagui nearly three miles in a northerly direction'. ${ }^{22}$ Then commonly known as 'Long Lagoon', it was described soon after the discovery of lowland gold as:

a fine sheet of fresh water, over 60 chains long, and, perhaps, half as wide, which is situated a few chains from the beach diggings ... [that] now serves the population of Bermagui with all the water required for domestic purposes. It is nine feet deep in parts and undoubtedly is permanent.

From higher slopes, a flying fox carried ore from Gulaga down the valley for crushing - a true land of flying fox and drifting sands. With both timber and water plentiful, 'it did not take long to arrive at the conclusion that Bermagui was a favourable place for settlement'. ${ }^{23}$

Bermagui was built on the exploitation of natural resources. Beyond mining, grazing of hard-hoofed animals has had a severe impact on local ecosystems since settlement. Watering of cattle in freshwater bodies disturbed delicate soils, causing significant turbidity and damage to habitat and ecological processes..$^{24}$ Until its closure in 1977 , the town was home to a large timber mill and was a significant player in the forest industry of the region. While the mill has closed, forestry continues in the region. The Bermagui State Forest is managed by the forestry industry, its trees destined for chipping or milling. Activists continue to fight for the reservation of the remaining spotted gum (Corymbia maculata) habitat, calling for it to be turned into a National Park. The edge of the continental shelf is just 11 nautical miles from the shore,

21 'Bermagui', Sydney Mail and New South Wales Advertiser, 16 October 1880, 736-7.

22 'Latest Mining Telegrams', Australian Town and Country Journal, 2 October 1880, 12.

23 'The Bermagui Gold-field', Sydney Morning Herald, 8 October 1880, 7.

24 For more on the significance on damage to waterholes in settler history, see C. Muir, The Broken Promise of Agricultural Progress (New York: Routledge, 2014). 
making Bermagui popular for recreational and commercial deep-sea fishing. It was made famous on the world stage in the global game fishing community by the American writer Zane Grey who visited Bermagui in 1936. ${ }^{25}$

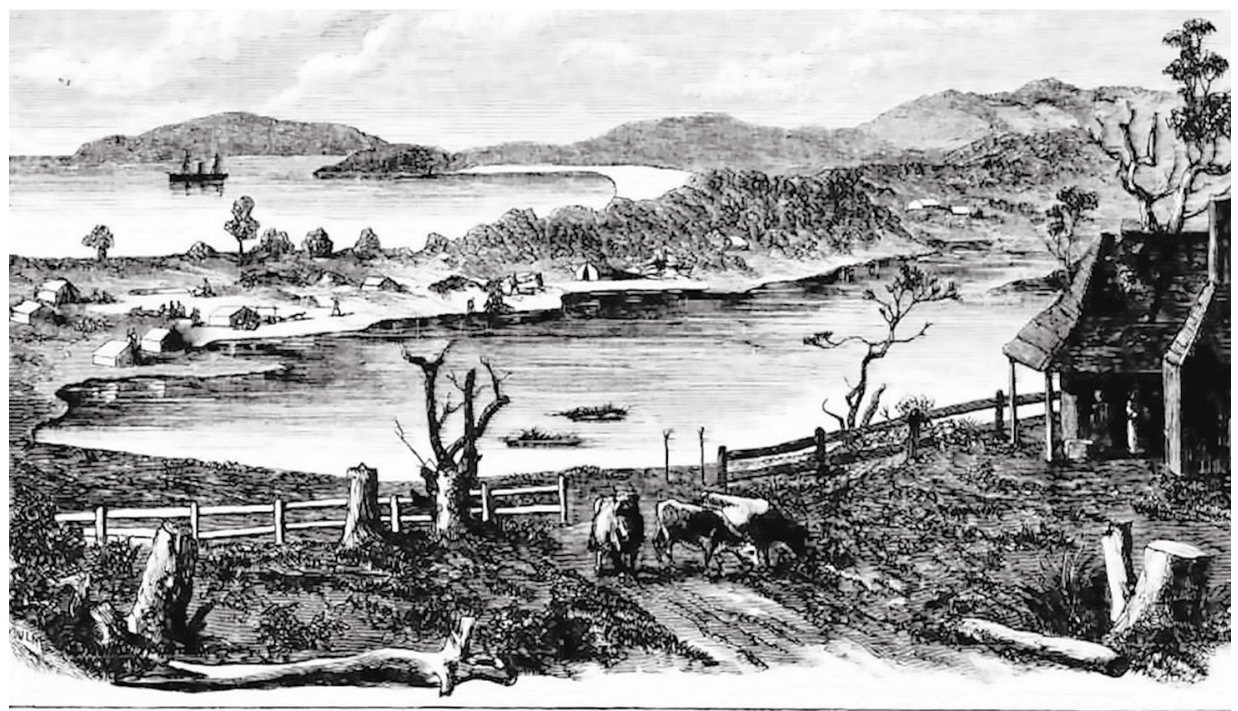

VIEW FROSH ELTHEMINGTON'S SELECTION OF THE LONG LAGOON AND DERMAGUI HEAD.

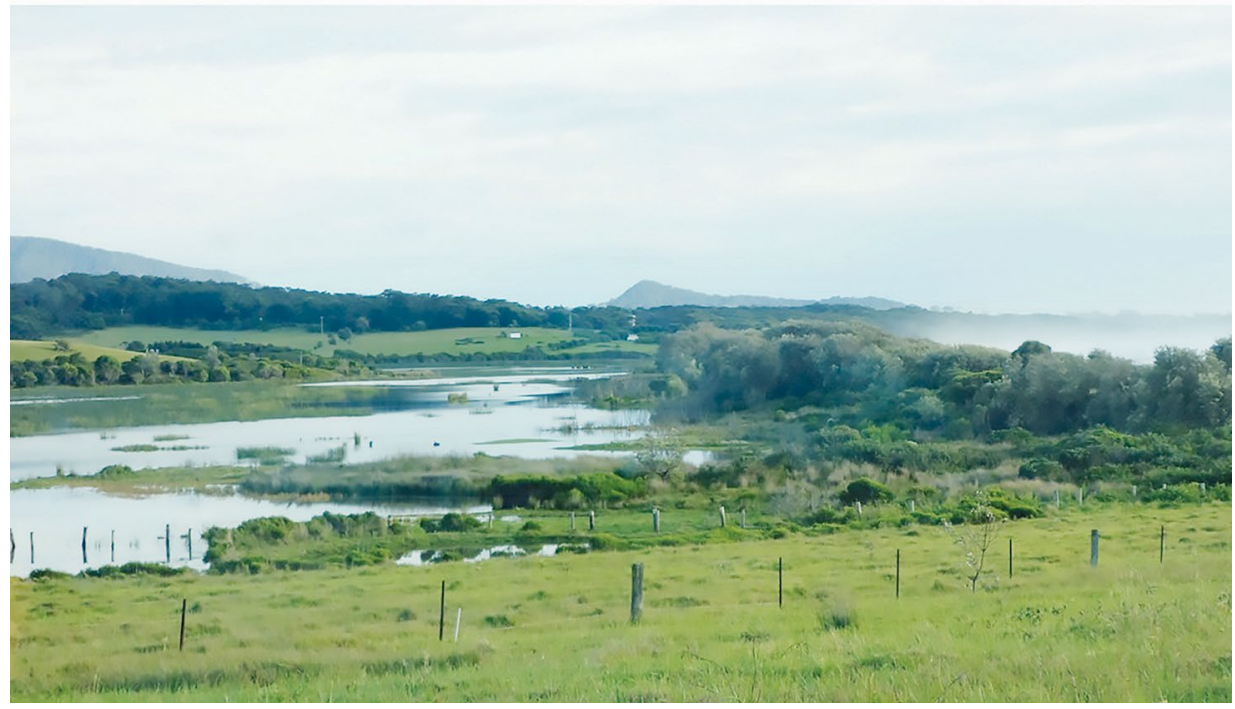

Figure 1: Top: Long Swamp (looking south-west) in 1880; Bottom: restored Long Swamp (looking north) in 2015

Sources: Top image: The Sydney Mail and New South Wales Advertiser, 16 October 1880, 736; Bottom image: The author.

25 Z. Grey, An American Angler in Australia (New York: Harper and Brothers, 1937). 
Grazing, clearing and mining have all contributed to significant modification of Bermagui's environment since the mid-1800s (see Figure 1). An article in the Sydney Mail in October 1880 stated: 'The claims on this part of it [the beach] are badly placed, being between two bodies of water, and, as the rock is below the level of the lagoon, will always be subject to floodings'. Still, proximity to the coast did not stop gold prospectors. Periodically, storm surges and drifting beach sand have impinged on the permanent coastal settlement, threatening freshwater sources and economic sustainability of the town. ${ }^{26}$

The crumbling tarmac of Old Tilba Road is a material reminder of the ongoing settler misunderstanding of the dunes and variability of the ocean. In 1971, unusually high tides washed away part of the road. Erosion of the dunes continued, accelerated by waves, until large sections of the road collapsed. In 1973, the land between Long Swamp and Haywards Beach became Crown Reserve 88847 and was handed to the management of the Bermagui Environment Group (now the Bermagui Flora and Fauna Reserve Trust (BFFRT)). In 1975, the road was closed, but the road itself was not included in the crown reserve. A local council proposal in 1991 to reopen the road aroused local 'anger and dismay' among those with a longer-term memory of the issues of its location on a primary dune, including pre-collapse banks of sand that would drift over the road making it unusable for transport of people, or indeed stock. ${ }^{27}$ Calls to develop the road to cater for cars or bikes recur intermittently. Today, the road forms an integral part of the reserve, and restored vegetation creeps over the remaining tarmac (Figure 2). The BFFRT is tasked with protecting the native flora and fauna at both Long Swamp and Bermagui North Lagoon. The restored Long Swamp and the surrounding land and dune system host a diverse suite of species (both locally endemic and migratory), and are protected under the NSW State Environment Planning Policy Number 14 (SEPP 14) for coastal wetlands.

Just south is Cuttagee Point, where potatoes and peas used to grow high above the exposed coastal cliff. The headland was used for grazing and farming between 1877 and 1976, when it was acquired by the NSW Government and became a crown land reserve. The very tip of the headland forms part of Biamanga National Park (established 1994), which in May 2006 was returned to the Yuin people and is jointly managed with the National Parks and Wildlife Service. The volunteer group Bermagui Dune Care has worked on the site since 2012, liaising with responsible managers and receiving small grants to fund their volunteer work, which is made up primarily of general tidying, planting and weed clearing (Figure 3). Their local sign lists their aims to 'restore native vegetation, increase biodiversity, preserve vehicular

26 'Bermagui', Cobargo Chronicle, 19 January 1924, 2.

27 'Road re-opening angers residents', Bega District News, 6 August 1991, 6. 
access, and improve viewpoints and information'. ${ }^{28}$ The regular attendance, maintenance and vision brought by the expertise and passion of the group has led to a resounding ecological improvement of the point.

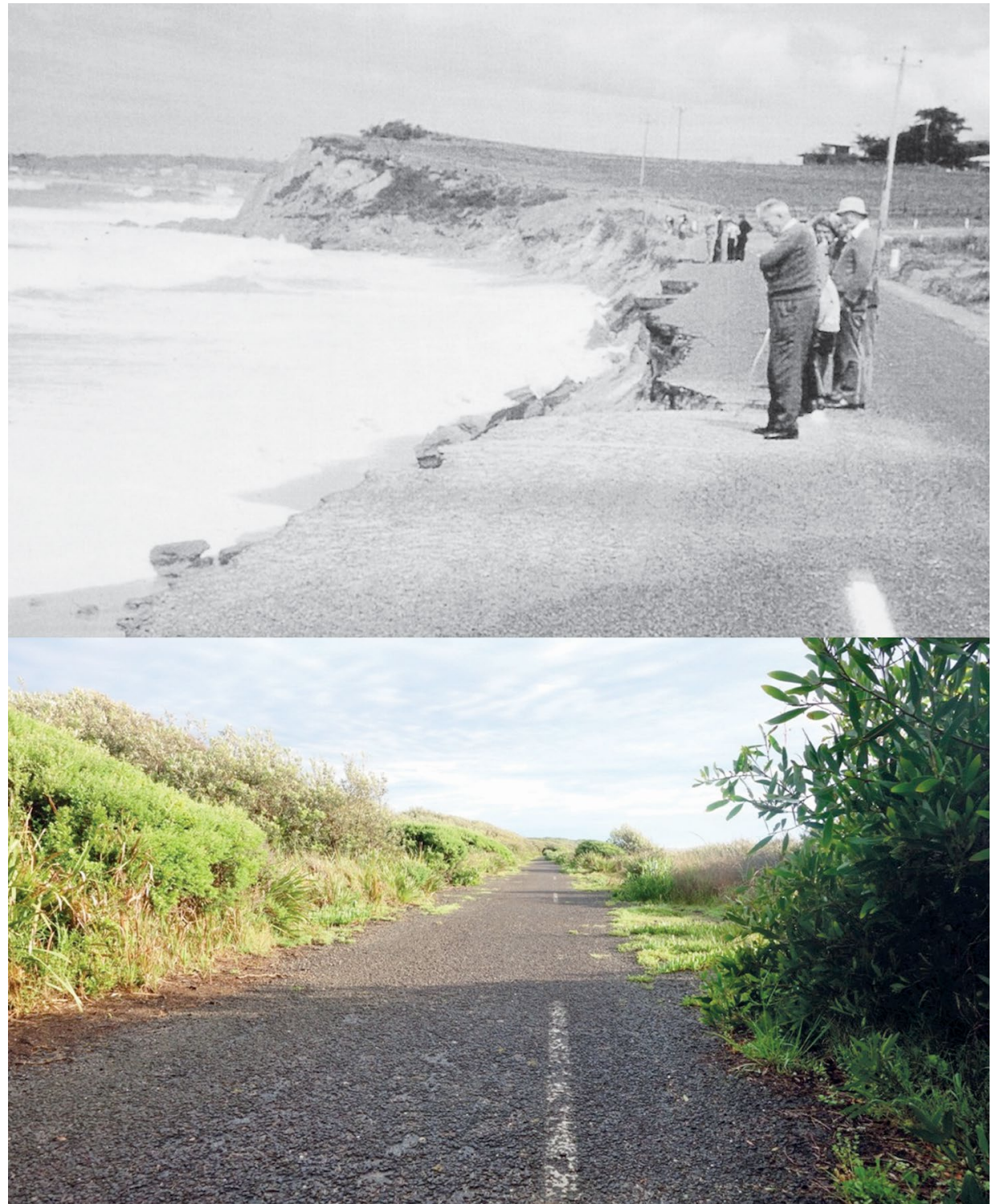

Figure 2: Top: Old Tilba Road (looking south) after storm surge c. 1974; Bottom: Old Tilba Road (looking north) after restoration efforts, 2015

Sources: Top image: From colour slide by the late Sister Harris of Bermagui, reprinted with permission of the Bermagui Historical Society, BFFRT archives; Bottom image: The author.

28 Cuttagee Point and Bermagui Dune Care information is detailed on a sign titled 'Restoring Cuttagee Point' in location, viewed on multiple visits, November 2015. 


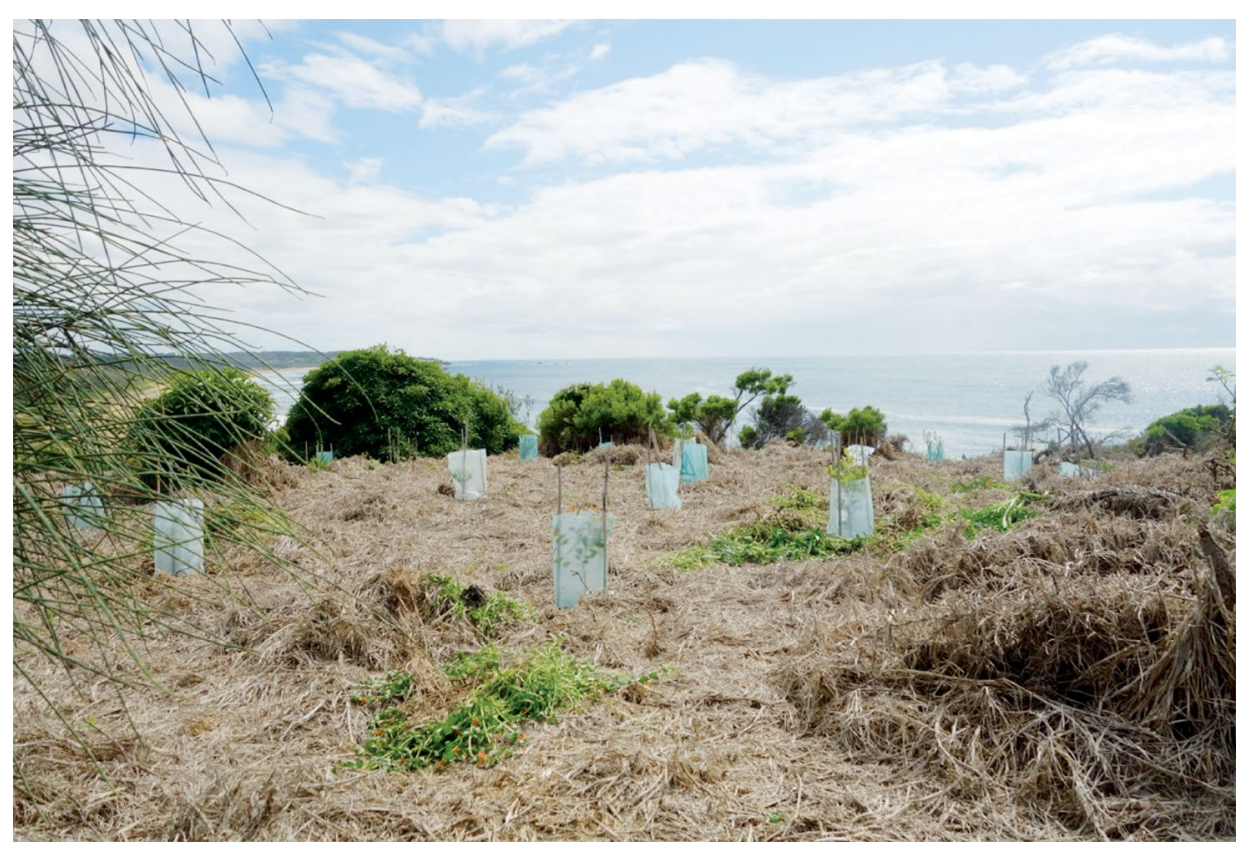

Figure 3: Recent plantings by Bermagui Dunecare on Cuttagee Point, 2015 Source: The author.

Amidst the pigface (Carpobrutus glaucescens), banksia (Banksia integrifolia) and paperbark (Melaleuca ericifolia/M. armillaris) are people. Some are on their knees, gently sorting one plant from another, pulling out those not welcome. Some are hauling away plastic guards that contort seedlings, removing the obvious evidence of human hands at work. The shock of a thistle spur that gets through your gloves, the fragrant mix of sunscreen and dirt, familiarity with sclerophyllous foliage and pigface flesh all build experiences of cooperation and cohabitation in the local environment.

As the environment continues to change and the waves roll further into shore, sharp definitions of ecological belonging are being washed away. Questions arise that demand answers beyond those bounded by fixed histories. Old photographs, maps, local tales and personal observation make up narratives of historical validity; expert science, ecological modelling and mapping add vigour to activities, but it is within the affective experiences of restoration that fresh perspectives on settler ideas of place erupt. The following five emotional practices demonstrate how affective experiences of restoration within place can open dialogue to plural ontological and epistemological perspectives and shift the path of dominant histories. 


\section{Loving}

'People love these places ... so that's why they want to look after [them]. It's not just economic and so on', says Bruce, one of the volunteers. I am told about regular, sometimes daily visits to their sites. For many volunteers in Bermagui, restoration provides a reason to get outside, a hobby and a supportive social network. ${ }^{29}$ In the mid-morning, the group takes a rest over a thermos of tea, cakes and biscuits, and together we reflect on why they are involved. Glenn says he loves 'working with a bunch of like-minded people', who value the wetlands and the coast for their 'intrinsic value'. Many of the volunteers love the hands-on aspect of their work. Alana tells me that she 'love[s] being outside and doing physical work'; Penny describes how her 'fingers get itchy' when passing weeds. Great satisfaction comes from existing in a reciprocal and generous relationship with the environment. ${ }^{30}$ 'I think', says Chris, 'everybody feels that they want to be involved in helping the environment but we also get rewards in seeing the plants growing. Planting is just so heartening. You sort of feel good after it.' Bruce tells me, 'I walk along the coast now and think: Oh, gee-look how different that is, and I was part of that! [laughter]. It's a great feeling.' 'I always find that the land is my connection ... so when I retired I wanted to make sure that in my voluntary work I was giving back to the land', says Alex.

\section{In Sarah's understanding,}

it was like Europe, for centuries and centuries, you know-you flatten it, you concrete it, you build a road, you build a factory, you build a house, you cut down the trees, you burn them, you make them into something. Oh there's fish, quick, you kill them, you eat them, you know ... so in some ways I feel like this is our little bit of healing, is to somehow say ... we give back to this land its natural state.

Of course, different values of 'nature' co-exist, revoking blind hope for full ecological enlightenment. In the 1880s, as locals showed an appreciation of local plants (see Figure 4) they also severely degraded the environment through their resource demands; this co-existence continues today.

29 See also Higgs, Nature by Design for discussions about ecological restoration and community strengthening.

30 The notion of reciprocal relationships is inspired by R. Kimmerer, 'Restoration and reciprocity: The contribution of Traditional Ecological Knowledge', in Human Dimension of Ecological Restoration, ed. D. Egan, E. Hjerpe and J. Abrams (Washington, DC: Island Press, 2011). 


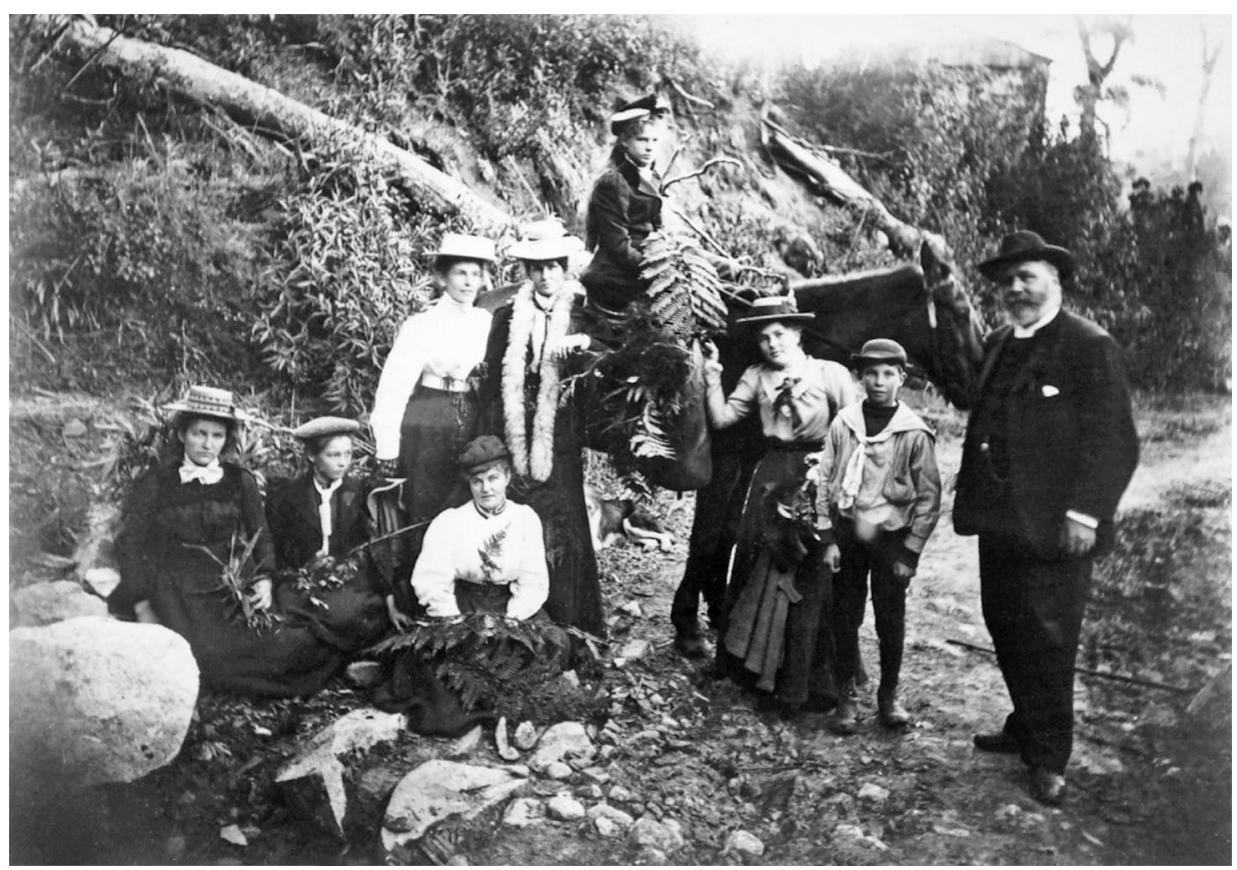

Figure 4: Group on Gulaga along Tilba Track, c. 1889; note collection of ferns and orchids

Source: Bodalla State Forests, Document No. 606: Mount Dromedary Flora Reserve No. 79948 Working Plan, TT 134 28, BFFRT archives.

Restoration practice satisfies a human need for cultural and natural connections, and cultivates caring relationships with what the scholar Donna Haraway refers to as 'non-human kin'. Love and commitment to place cultivates a rich sense of belonging. From such a position, one is exposing oneself to stress, grief and loss. ${ }^{31}$ In 1974, the scholar Yi Fu Tuan coined the term 'topophilia', literally 'love of place', and in 2005 the scholar Glenn Albrecht developed the related term 'solastalgia'grief over loss of a sense of place. ${ }^{32}$ These volunteers are not afraid to fight hard for the places they look after, but, through commitment and care, new kinds of vulnerability are also forged. The love and care experienced in restoration is critical to shifting relationships within and with the local environment-responding to and contrasting with extractive settler histories.

31 Van Wieren, Restored to Earth; D. Haraway, 'Anthropocene, Capitalocene, Plantationocene, Chthulucene: Making Kin', Environmental Humanities 6 (2015): 159-65, doi.org/10.1215/22011919-3615934.

32 Y. Tuan, Topophilia: A Study of Environmental Perceptions, Attitudes, and Values (New York: Columbia University Press, 1974); G. Albrecht, 'Solastalgia: A new concept in health and identity', Philosophy Activism Nature 3, no. 1 (2005): 45-55. I use the term 'love' intentionally throughout to encourage the discussion of love and other emotions in environmental debates, often resisted. See C.-A. Morrison, L. Johnston, L. Longhurst and R. Longhurst, 'Critical geographies of love as spatial, relational and political', Progress in Human Geography 37, no. 4 (2012): 505-21, doi.org/10.1177/0309132512462513. 


\section{Labouring}

Ecological restoration is both physically and emotionally demanding. As Higgs has pointed out, the physical work and decision-making can be onerous. ${ }^{33}$ In 2003, the NSW Government estimated approximately 10,000 people were involved in voluntarily managing the state's crown reserves, significantly propping up environmental management. ${ }^{34} \mathrm{~A}$ 'reserve trust' under Part 5 of the Crown Lands Act 1989 is a body corporate appointed to manage a reserve. Forming an independent body of the government, arduous paperwork and accountability are called for. On top of their physical labour, volunteers juggle responsibility to crown lands, relationships with the local community and competing land uses. There are concerns about the ongoing energy in volunteer groups.

Most of the volunteers in Bermagui are elderly or retired. Chris worries that 'there doesn't seem to be any younger people coming in'. She says that many activities in Bermagui rely on volunteers but people are already committed to other causes and young people are often busy with the demands of family life. Increasing strains of menial managerial roles, such as occupational health and safety compliance, insurance and paperwork, are taxing on volunteers and discourage participation. Rob tells me, 'you get people off side for not giving them credit for being sensible and safe'. Penny wonders why people need to join an organisation to have their awareness, consciousness and commitment raised, and sees opportunities to get involved as limited, saying, 'environmental work is for the privileged'. As is common in all social groups, work-imposed stresses and clashing characters influence the experience. The amount of local knowledge relied on, the power in personal relationships for getting things done and the passion of individuals looking after their own place create risks associated with the loss of key individuals.

For emotional stamina, it is important that volunteers believe in the benefits of their labour, yet the task of ecological restoration is often overwhelming and relentless. This is particularly the case for weeding, which requires constant repetition. Penny says, 'Sometimes you just feel: Oh, my goodness, how can we do this? How do you get on top of that? Informality and tenuousness of resourcing and capability for weed control plagues environmental management'. ${ }^{35}$ As Alex says, 'it's daunting, you know, where do you start? And I know it's best from [previous experience] that you just start in one little section and move on'. This is one of the principles of the Bradley Method, established in Australia in 1988, that proposes moving 'at the pace of nature through space, from the most intact bush out to the most degraded areas', because, as its developer Joan Bradley put it, 'nobody likes weeding the same piece

33 Higgs, Nature by Design.

34 Department of Lands, 'Trust Board Members Application for Appointment Advertisement' (2003), 5, BFFRT archives.

35 Head et al., 'Living with invasive plants', 316. 
of ground over and over again with precious little to show for it'. ${ }^{36}$ The Weeds Project has attended to the more arduous weed removal along the coastline. ${ }^{37}$ The project, celebrated for its contribution to employment and training for local Indigenous peoples, works with representatives from respective land councils in the different sections of the coast. Since the efforts of The Weeds Project began to have an impact, the Dune Care group do not have any weeding to do on the beach, so they have been able to turn to planting. 'It's still hard work', says Chris, 'but you know they're going to grow and shade out the weeds.'

Restoration work is often slow and reactive rather than fast and proactive. The environment keeps participating, creating ongoing and unpredictable challenges. Even when funding is available, the slow turnround time of funding grants means immediate needs are often not met. Volunteer groups are vulnerable to community criticism by those who want to see constant progress.

I feel negative but progress ... there must be progress, there must be. Well there islook at those pictures back there, and then look at this. So there is progress, it's just slow. And people are very quick to criticise too ... people will walk along here and say 'what are those people doing?' (Penny).

It is important for onlookers and participants to remember that these individuals are volunteers doing the best they can. Otherwise, as Alex warns, 'it can become overwhelming ... then people drop out'. Some volunteers are frustrated that their labour is propping up local tourism, infrastructure, health and education without being adequately recognised or supported. An ethical shift from a colonial narrative of 'progress' and 'improvement' to one of co-creation, patience and endurance is evolving, but goes largely uncelebrated.

Physical and emotional exhaustion needs to be balanced by hope. Since restoration efforts at Long Swamp began, a range of water birds, including some significant migratory species previously sullied by habitat decline and shooting, have returned, spurring people on. As Rebecca Solnit has written, 'to hope is to give yourself to the future, and that commitment to the future makes the present habitable. Anything could happen, and whether we act or not has everything to do with it. ${ }^{38}$ It does not take much to look at an old photograph, or make time to tell stories about how things used to be in order to acknowledge success - and it is an important step both for the group and for the wider community.

36 J. Bradley, Bringing Back the Bush: The Bradley Methods of Bush Regeneration (Willoughby, NSW: Ure Smith Press, 1988), 21.

37 See S. B. Cameron, 'The Bega Valley Shire's coastal weeds project', Australian Plant Conservation 20 no. 2 (2011): 15-16.

38 Duck-shooting announcements and numbers are documented in many news articles. For example, see 'Mumbulla Shire Council', Cobargo Chronicle, 26 February 1916, 2; R. Solnit, Hope in the Dark: Untold Possibilities, Wild Histories (Chicago: Haymarket Books, 2004), 5. 


\section{Learning}

Through restoration practice, people get to know a place. They come into relationship with its biophysical features, stories, cultures, memories, histories and spirit. The anthropologist Deborah Bird Rose has argued: 'Earth language is never monological; always relational, it is a call to enter into encounters, to be co-present and engaged', encouraging us to 'listen in multiple registers' ${ }^{39}$ The act of restoration requires multi-sensory listening and learning. The philosopher David Abram suggests that 'each ecology has its own psyche, and the local people bind their imaginations to the psyche of the place by letting the land dream its tales through them'. Geography is not merely a subject of place identity, but is also alive with stories integral to forming place attachment and understanding. Sarah said, 'I see sugar gliders, there are more snakes, I can hear the cacophony of frogs at night ... I can only go on what I have seen ... I can read historical things but I have no visual or verbal proof of that'. ${ }^{40}$

Ecological restoration in Bermagui nurtures a place-based form of local knowledge as a counterpart to 'expert science'. Sarah described her mission in Bermagui as 'to put back what had been taken away around town'. The BFFRT has commissioned ecological reports to establish the characteristics and ecological values of the area. Examples include Bermagui Flora and Fauna Reserve Bushland Survey (1986), Fauna and Flora Assessment: Bermagui Flora and Fauna Reserve (1997) and The Limnology of Long Swamp (1997). ${ }^{41}$ These documents guide restoration activities, establish benchmarks for measuring success and provide scientific legitimacy that underpins grant applications. Yet different forms of knowledge emerge through practical experience, and monitoring occurs from having eyes, ears and feet on the ground. As the ethicist Gretel Van Wieren has written, 'restoration activities provide a context [for] people to learn from the other wild beings and processes that shape their own and other creatures' lives. ${ }^{42}$ Alana shared her observation that 'being in there more often means that I'll see more ... enjoy it more, in a more sort of tactile and visual way'. Penny told me, 'what I'm enjoying most is getting to know the wetland, getting to know the flora and fauna and feeling more connected to it'.

\footnotetext{
39 Rose, 'Val Plumwood's philosophical animism'.

40 D. Abram, 'Earth Stories: Ecology', Resurgence 2, no 22 (2004): 21. See also B. Lopez, 'A Literature of Place', US Society and Values 1, no. 10 (1996), 12; E. Relph, Place and Placelessness (London: Pion Limited, 1976); H. G. Gadamer, Truth and Method (New York: Crossroad, 1982). In a Heideggerian manner, Gadamar argues that our experience of the world is constituted by our 'situatedness', mediated by our horizon of understanding, implicating the biophysical sphere in the intricate relationships we have with the world.

41 J. Blay, Bermagui Flora and Fauna Reserve Bushland Survey (Sydney: National Trust (NSW), 1986); G. Daly and G. Leodard, Fauna and Flora Assessment: Bermagui Flora and Fauna Reserve, Bega Valley Shire (Cambewarra, NSW: Gaia Research Pty Ltd, 1997); B. Timms, The Limnology of Long Swamp (Newcastle: University of Newcastle, 1997), BFFRT archives.

42 Van Wieren, Restored to Earth, 132.
} 
The management of carp in Long Swamp provides an example of how ecological restoration can draw on local ecologies and environmental history. Carp (Cyprinus carpio) were introduced to Long Swamp by local property owners in the early twentieth century, a time when acclimatisation societies thrived. Their intention was to provide fishing opportunities as part of a planned caravan park. It is now known that carp increase water turbidity and drastically impact Australian freshwater ecosystems by altering the ecology and excluding many native species, making their eradication an obvious task for ecological restoration. ${ }^{43}$ The proven method of eradicating carp-draining the wetland and covering the surface with lime to kill off any life-was unacceptable to the group, due to the impact on other species. Instead, they developed a successful place-based approach that entailed local culture, the agency of the natural world, and a positive interpretation of drought. Sarah explained their thinking thus:

we were in a fishing town, there's a regular fishing competition: why don't we pay the fishermen to have competitions to fish out the carp a couple of times a year, going for the most fish caught, the biggest fish caught? ... So we had that happen several years, back to back, until there's a point where basically they weren't catching anything ... At the same time nature was on our side, because we'd had a drought, so as a group we decided to put one, two, three, four, I think, bird perches into the wetlands. Now, cormorants came to those perches straight away, and we figured that they would fish out any fingerlings that hatched.

Another species that was the target for eradication was marram grass (Ammophila arenaria). About 1911, marram grass was planted in stages in an attempt to stabilise coastal dunes and reduce drift sand. This was an early rehabilitation action in response to the effects of clearing local vegetation. An article in the Cobargo Chronicle in January 1924 applauded the project:

The trustees of the recreation ground are to be congratulated on their success in arresting the drift of beach sand by the planting of marram grass ... There was a danger a couple of years ago that the drift of a big wave of sand would pour through the forest trees on the ground and kill them out in a face. This danger has been averted. Carry on the good work, Sam. ${ }^{44}$

It is now understood that marram grass competes with native grasses, and has sandbinding properties that can result in dunes becoming steeper. After its successful colonisation and spread, it is now considered an environmental weed and is actively removed from Australian coastal habitats. This is an example of how ecological learning has come in waves, moving further now towards that of ecological systems thinking where a fast functional fix is not enough.

43 See M. J. Weber and M. L. Brown, 'Effects of common Carp on aquatic ecosystems 80 years after "Carp as a Dominant”: Ecological insights for fisheries management', Reviews in Fisheries Science 17, no. 4 (2009): 524-37, doi.org/10.1080/10641260903189243.

44 'Bermagui', Cobargo Chronicle, 19 January 1924, 2. For more information, see Eurobodalla Shire Council, 'Beach weeds', www.esc.nsw.gov.au/living-in/about/our-natural-environment/introduced-plants-and-animals/weeds/ weed-profiles/beach-weeds, accessed 1 November 2017. 
Imported cultural epistemologies, such as the European seasonal calendar, come into question through restoration practice. Alana tells me, 'I learned ... about the changes in it too, like the changes in the water level, and different times of the year look different from others'. Alex says, 'we're still sort of fitting in with the four seasons as set up by the British, whereas a lot of the Aboriginal people, I mean, they'll have anything from two to eight ... why do we still set ourselves ... against a country that's miles away? Why can't we learn?'45 The philosopher Lucien Levy-Bruhl noted in 1938 that 'a sacred spot never presents itself to the mind in isolation. It is always part of a complex of things which include the plant and animal species which flourish there at various seasons ... and all the emotions aroused by the whole. ${ }^{46}$ By engaging with local ecologies, special places are emerging. There is a calm, liminal place, under wind-blown tea-trees (Leptospermum continentale) where Penny stops: 'It's a place of silence. We should be quiet.'

Restoration also teaches people how to engage with their place in ways that challenge both extractive relationships and preservationist ideas of wilderness. Alex says, 'I love walking past and seeing some really good lomandra [Lomandra longifolia] ... just seeing what's around me that-I mean, I can't use it from here because it's a reserve but I'm constantly looking to see'. Later, she stops to point out local food plants, warrigal greens (Tetragonia tetragonioides) and pigface. Alex hopes that through restoration she can address oversights entailed in settler notions of the bush, saying, 'I feel quite ashamed in a way that we've been in this country for all these years but my knowledge of bush tucker food is minimal, so I want to increase my knowledge ... so I can protect those things and not think of them as a weed'. The BFFRT does not use chemical spray, to ensure that 'bush tucker' is safe to eat. Local school children come here to learn from the environment about ecology and about Yuin culture.

A lack of local observation and understanding of ecological processes among settlers contributed to allowing unchecked destruction, as well as misinformed management. Over time, through being in touch with the land, local knowledge has developed that contrasts with the hegemony of expert-led Western science. So, too, has a realisation of the potential for local Indigenous knowledge and culture to participate in ecological restoration. Possibilities to weave together the environment and the broader community come from being in place. There is a risk that through the use of Western science to support and validate their work, volunteers undervalue the importance of knowledge that comes from being in place, that only time and experience can spawn.

45 In 2016, the Australian Bureau of Meteorology launched an interactive tool to promote Indigenous weather knowledge. See www.bom.gov.au/iwk, accessed 1 November 2017.

46 L. Levy-Bruhl, 1938, quoted in R. Sheldrake, The Rebirth of Nature: The Greening of Science and God (London: Century, 1990), 148. 


\section{Limiting}

Ecological restoration excludes unwanted others, with ethical and political consequences. ${ }^{47}$ Living nearby, Bruce looks after what he describes as his 'own territory'. Species, practices and conflicting human values are carefully screened. A 1992 article in Coastal Focus, a newsletter for community groups along the NSW coast, explained, 'People living along the coast of NSW often feel they live in "a little bit of paradise" and when forces of destruction threaten, they fight back. ${ }^{48}$

This coastline has a history of repeated conflict between the values of industry and those of conservation. A 1993 Department of Water Resources, Water Policy Division community guideline development process captures some conflicting responses to local wetlands. Participants said, 'individual wetlands need to be managed separately'; 'a universal approach is needed', 'grazing is an important value of wetlands' and 'wetlands have an intrinsic value'. ${ }^{49}$ Restoration practice unites people in their care for local ecosystems in a way that overcomes differences. In this way, it cultivates an ethic of reciprocity that counters capitalist framings of the 'value' of a place. Sarah says, 'When you talk to people in town, even businesses now, who're interested in money money money, [they] say "where can we go as a town?"- this was a resource town-this is a logging, fishing town. Totally a resource town'. Through ecological restoration, volunteers are demonstrating, and fighting for, a different relationship with the natural world.

On 4 June 1999, the second stage of fencing Long Swamp was completed. This defined property boundaries and excluded neighbouring cattle from using the wetland as a water source. For a local family who had used the wetland for watering their animals for generations, particularly in drought times, this was a great blight on their history as well as a practical inconvenience. The exclusion of stock quickly demonstrated how a small intervention allows dramatic repair. Rob says, 'I sometimes think that we didn't actually have to do anything other than fence it off. The melaleucas and the banksias all self-seed very efficiently'. While some neighbours are willingly establishing buffer zones within their properties to accelerate healing, others still resist these management approaches. ${ }^{50}$

47 See Trigger et al., 'Ecological Restoration, Cultural Preferences'.

48 'Editor's Note', Coastal Focus (Total Environment Centre, Sydney) (March 1992), 1.

49 NSW Department of Water Resources Water Policy Division, Guideline development process: Wetlands (1993):

4-7, BFFRT archives.

50 L. Instone, 'Fencing in / Fencing and: Fences, sheep and other technologies of landscape production in Australia', Continuum: Journal of Media and Cultural Studies 13, no. 3 (1999): 376, doi.org/10.1080/10304319909365808. Instone's work on fences invites dialogue about boundaries, ownership and identity, specifically bringing new readings of place that expose 'cultures and natures rendered invisible and silent in the colonial story' (372). 
The success of the restoration work has created an environment that is once again desired and more attractive to developers. Alana said, 'the road was washed out twice and then the Council just gave up and said: OK, you can have it, but then they want it back ... twenty years later they want it'. Demands to cater for dog-walking, cycling and fishing repeatedly challenge the ecological focus. In June 2000, there was a plan for 2,000 bass fingerlings to be introduced to Long Swamp to provide recreational fishing opportunities. How short the memory and recurrent the dream of an introduced fish frenzy. The BFFRT argued successfully against this plan, on the basis that bass would threaten littoral invertebrates, zooplankton and amphibian species, leaning too on the legislative powers of its SEPP 14 listing. In this context, local environmental histories (in order not to repeat mistakes of settlement past) and stories of human involvement (so as not to present a wilderness ripe for the taking) are vital.

Actively managing and marking land has been a strong part of the colonial project. Now the active mark is being used in order to defend a place for nature. ${ }^{51}$ Volunteers emphasise the need to keep it 'natural', while establishing a strong presence through signs and events so that there is less pressure from competing groups. 'It makes it look like something is being done', says Rob, jesting, 'what I would like to do is put a bloody chain-mail fence across either end of the road and keep people out, and then it'd look after itself very well'.

Weeding, a foundational aspect of most ecological restoration projects, continuously enacts territorial exclusion. While weeding on Cuttagee Point, a question is asked about whether a species is 'one that belonged or not', and deemed 'a legitimate local grass' that is to be spared. Weed management decisions are triaged due to limited resources, meaning that many non-native species are reticently accepted. Inkweed (Phytolacca octandra) is a perennial herb with a shrubby habit that is listed as an environmental weed in the local Eurobodalla Shire. Its seed is spread by birds-likely the same ones that are flitting about over our heads as Bruce cuts it back. 'I don't want to destroy it', he says, 'just subdue it a bit. ${ }^{52}$ In a 2014 report on weed infestations written for BFFRT, there is long lists of species assessed as of low concern. ${ }^{53}$ These are carefully distinguished from those with a demonstrated capacity to modify the landscape or soils that are prioritised by local land managers. The management of weeds is considered according to each sites' unique characteristics, but clear

51 See N. Blomley, 'Un-real Estate: Proprietary space and public gardening', Antipode 36, no. 4 (2004): 614-41, doi.org/10.1111/j.1467-8330.2004.00440.x.

52 See www.esc.nsw.gov.au/living-in/about/our-natural-environment/introduced-plants-and-animals/weeds/weedprofiles/inkweed-phytolacca-octandra, accessed 24 November 2017.

53 S. B. Cameron, A report on weed infestations in the Bermagui Flora and Fauna Reserve-Bermagui North Lagoon (Bermagui, 2014), BFFRT archives. 
'native' and 'exotic' definitions to colonially informed baselines of belonging are fading. Instead, species are beginning to be approached from an ecological systems perspective:

Like these thistles, for instance ... they're a response to spraying the kikuyu [Pennisetum clandestinum] and I think ... that there's a clump of them that seem to be defending a small banksia against browsing ... sometimes you can use things like that and ... also if we grubbed out here, if we managed to grub out every thistle that was here, we'd still have just as many next year, I'm sure. (Bruce)

Navigating different values within a community is a hard reality for groups working on public land. Philosophical debates about what belongs and how much they should be resisting change regularly come up in decision-making. Sometimes exceptions are made for social reasons, such as retaining some 'exotic' trees that were planted as memorials, giving them cultural value. Decisions about territory invite reflections on settler belonging: 'And we're feral?' asks Sarah, 'cause we say we're Australian!' Ecological restoration can respond to the degradation of past and aim for a resilient and diverse system, but it operates within contested landscapes layered with histories.

\section{Letting go}

Through ecological restoration, people are able to learn from the environment about change, acceptance, impermanence and letting go. Emphasis is placed on the practice itself rather than fixed outcomes. In the 1991 annual report of the Conservation Council of the South-East Region \& Canberra, acting President Graeme Evans wrote, 'Adaptation to new circumstances will sometimes provide a continuity with the past which strict adherence to established forms would leave shattered'. ${ }^{54}$ In this way, restoration can be a practice of absolution from control, as expressed through the following examples of sweet pittosporum (Pittosporum undulatum) movements, the egg-laying habits of turtles and sea-level rise.

At multiple points along the coast, sweet pittosporum is proliferating, forming thickets of dense green foliage amidst tea-tree, spotted gum and banksia. Without ecological burning, and with ongoing dispersal by birds, it is expanding its ranges far beyond documented historical limits, out-competing other native plants. This species has created dilemmas for environmental managers across eastern Australia. ${ }^{55}$ At Cuttagee Point, the numbers of sweet pittosporums are increasing. They are not the only rainforest species thriving under the current management regime.

54 G. Evans, in Conservation Council of the South-East Region and Canberra, AGM report (1991), 1, BFFRT archives.

55 Cook and Lane, 'Rethinking Rural Amenity Ecologies'. 
The plantings at Cuttagee Point include more lilly pillies (Syzigium spp.), which are at the southern end of their range. This was done consciously to take account of shifting ecological ranges, but in a measured way. Bruce says he 'wouldn't go about deliberately you know, constructing a wholly new environment', but he is realistic about the role people have had to play in ecological change:

In effect we've changed the land form and the fire regimes so I think-look, we just have to go with it. I'm not sort of purist in view to restore this to exactly the way it was pre-European - well in fact we don't even know about that because a lot of these headlands were kept burnt by Aboriginal people ... There could have been a thousand species here once, if you start talking about orchids and lilies and things, and there's no way that we can restore that. We don't know how. All you can do is put the structure back and let it go I think.

Long-necked turtles (Chelodina longicollis) lay their eggs far above the level of high tide. Complex land form and ocean processes mean turtles have evolved knowing that their eggs need to be far from the shore. Their movements are sensitively attuned to the flux of local environmental conditions. ${ }^{56}$ Like unexpected migrations of little penguins (Eudyptula minor) in urban Sydney, these turtles make their way through paddocks and fences into tended gardens and lawns to return to the place from which they came. ${ }^{57}$ Such ecologies remind people of the importance of living in Australian environments with full consciousness of infrequent extremes, and of commitment to place. Ensuing reflections challenge spatial boundaries and call on private land management for conservation of local species.

Today, sea-level rise is almost synonymous with climate change. The coastline has always been turbulent (recall Figure 2). The future of Long Swamp as a freshwater lagoon relies on the dune remaining intact—an unlikely event given long-term predictions. Alana says:

I think tsunamis will just take the whole thing out, um, sea level rise will just flood that whole bit, you know, I just ... I, I-if I think about it too much I just get depressed, so I kind of just (small sigh) I don't know (laughs) ... anything could happen in twenty years so I just yeah, try and live in the moment and appreciate it for how it is right now.

Despite awareness of the impact that rising sea levels and high tides will continue to have on Long Swamp, volunteers value the importance of caring for it in the present, driven by a deep love of their place.

56 J. H. Roe and A. Georges, 'Terrestrial activity, movement and spatial ecology of an Australian freshwater turtle, Chelodina longicollis in a temporally dynamic wetland system', Austral Ecology 33, no. 8 (2008): 1045-56, doi.org/10.1111/j.1442-9993.2008.01877.x.

57 T. Van Dooren, Flight Ways: Life and Loss at the Edge of Extinction (New York: Columbia University Press, 2015). 
In 2016, storms again pounded the NSW coast. Foam settled over the remnants of the road as the waves receded, taking much of the beach with them. The restored vegetation buffered the blow of the waves, but the long-term future of the coastline is precarious. Global climate change erodes the familiar, creating an experiential bridge from the local to the global, and providing a universalised justification for action. Alex says, 'I might not be able to affect the big picture, but I can work at the coalface and make a difference, and that makes me feel better'. Individual longings to respond to global environmental challenges are submerged in a group or collective sentiment that is reassuring. Many people spoke of the need to bring the land to good health and resilience-as Alex says, 'when the change that does happen ... these areas can still seed, blossom, do whatever they need to do'. From this study, it seems important to also encourage language and storytelling that turns towards commitment in the face of the uncertain and irrational — of that which is particular, and that which is love. ${ }^{58}$ The novelist Amitav Ghosh writes of the term 'uncanny':

no other word comes close to expressing the strangeness of what is unfolding around us. For these changes are not merely strange in the sense of being unknown or alien; their uncanniness lies precisely in the fact that in these encounters we recognise something we had turned away from: that is to say the presence and proximity of nonhuman interlocutors. ${ }^{59}$

Ecological restoration actively turns people towards the discourse between human and non-human others in constant renegotiation-through commitment, passion and grief. Such experiences erode settler mirages of human dominance and control, and, in its place, encourage place-based vulnerability and care.

\section{Restorative ecologies}

In Bermagui, settler extractive industries are eroding, like the road by high tides. The mill has closed, local mining has ceased, property values are pushing out grazing and many of the professional fishers are selling off their licences and being supported through work transitions by the government. ${ }^{60}$ In their place, coastal tourism, drawing on environmental, historical and cultural values, expands, bringing new trials and possibilities. The people portrayed in this piece who continue to care for the environment through a series of social and environmental challenges are important characters in the story of change over time. Their actions are personal and collective, rational and emotional, hands-on and mythic. They manifest what

58 Albrecht, 'Solastalgia'.

59 A. Ghosh, The Great Derangement: Climate Change and the Unthinkable (Chicago: University of Chicago Press, 2016), 30

60 See L. Smith, J. Becker and K. Honan, 'Unchartered waters for NSW fishing industry dealing with new government reforms', $A B C$ Rural, 1 June 2016, www.abc.net.au/news/2016-06-01/nsw-fishing-reforms-0106/ 7467330?pfmredir=sm, accessed 9 December 2016. 
Higgs calls 'focal practice', that fosters the philosopher David Strong's notion of 'correlational coexistence'. ${ }^{61}$ In this way, restoration can cultivate what the ethicist Daniel Spencer calls an environmental 'ethics of praxis', in which people are connected to the natural world in a reciprocal relationship by taking care. ${ }^{62}$

Restoration practice enters into a dialogue with embodied histories of landscape change, as understanding, decisions and successes are dictated by the past. ${ }^{63}$ By keeping their work rooted in local place and its histories-both told and untold-restoration practitioners can remain open to reflection and uncertainty, cultivating generous relationships with changing places. Ecological restoration is indeed 'rooted in ecological history'; yet, as the environment drifts, so too do the human relationships with place. In this context, committed local relationships become vital. ${ }^{64}$ The affective elements of restoration expressed in this article note the powerful component of emotions to the practice. Emotions engage history through another kind of healing potential: by dwelling in it, dismantling colonially framed imaginaries, and plotting out alternatives for ways of being with knowing and narrating place. Seen in this light, ecological restoration can be a powerful practice that attends to and disarms limiting ideas of history, contributes to a decolonisation of environmental management and increases meaningful responses to contemporary environmental tribulations.

\section{Acknowledgements}

Sincere thanks to Bermagui Flora and Fauna Reserve Trust, Bermagui Dune Care and the Bermagui Historical Society for participating in the study and providing access to archives; Libby Robin, Ruth Beilin and Cameron Muir for their supervisory support; Will Bakes, Margaret Cook, Tom Simpson and the two anonymous reviewers for valuable feedback on earlier versions of this paper; and Alessandro Antonello and Ruth Morgan for skilful editorship. This research was funded by a Christine Fifield Bursary (Capital Region Landkeepers' Trust), a Robert Lesslie Scholarship (The Australian National University) and an Australian Postgraduate Award.

61 Higgs, Nature by Design; D. Strong, Crazy Mountains (Albany, NY: State University of New York Press, 1995).

62 Spencer, 'Ethics and Restoration'; Van Wieren, Restored to Earth, 3.

63 Cooke and Lane, 'Rethinking Rural Amenity Ecologies', 228.

64 Jackson and Hobbs, 'Ecological restoration in the light of ecological history', 567-8. 
This text is taken from International Review of Environmental History, Volume 4, Issue 1, 2018, edited by James Beattie, published 2018 by ANU Press, The Australian National University, Canberra, Australia.

doi.org/10.22459/IREH.04.01.2018.11 